\title{
Impedance Spectroscopy for Annealing-Induced Change of Molybdenum Oxide in Organic Photovoltaic Cell
}

\author{
Toshifumi Kobori', Norihiko Kamata², Takeshi Fukuda² \\ ${ }^{1}$ Canon Electronics Inc., Saitama, Japan \\ ${ }^{2}$ Department of Functional Materials Science, Saitama University, Saitama, Japan \\ Email: fukuda@fms.saitama-u.ac.jp
}

How to cite this paper: Kobori, T., Kamata, N. and Fukuda, T. (2017) Impedance Spectroscopy for Annealing-Induced Change of Molybdenum Oxide in Organic Photovoltaic Cell. Advances in Materials Physics and Chemistry, 7, 323-333.

https://doi.org/10.4236/ampc.2017.78025

Received: June 17, 2017

Accepted: July 25, 2017

Published: July 28, 2017

Copyright $(0) 2017$ by authors and Scientific Research Publishing Inc. This work is licensed under the Creative Commons Attribution International License (CC BY 4.0).

http://creativecommons.org/licenses/by/4.0/

\begin{abstract}
Organic photovoltaic cells (OPVs) have been investigated for a long time, and practical realizations have been also in progress due to their high photovoltaic performance over $12 \%$. In this study, we fabricated normal OPVs and investigated the reason of an improved optical-to-electrical conversion efficiency by annealing the $\mathrm{MoO}_{\mathrm{x}}$ layer. The photoconversion efficiency was improved up to $5.65 \%$ from $2.05 \%$ after annealing at $160^{\circ} \mathrm{C}$ for $5 \mathrm{~min}$, and the external quantum efficiency also increased for all the measurement wavelength ranging from 300 to $900 \mathrm{~nm}$. Especially, the short circuit current density increased among photovoltaic parameters. The carrier transport resistance of photoactive layer was found to be reduced by evaluating the impedance measurement. These results indicate that defects at the $\mathrm{MoO}_{\mathrm{x}}$ /organic interface were successfully reduced by the thermal annealing process of $\mathrm{MoO}_{\mathrm{x}}$ layer. The efficient carrier transport was realized for the annealed-device, resulting in the high device performance. In addition, the relaxation and electron recombination times were also reduced by the annealing process, which lead to the improved photovoltaic performance.
\end{abstract}

\section{Keywords}

Organic Photovoltaic Cells, PTB7-Th, $\mathrm{MoO}_{\mathrm{x}}$, Annealing,

Impedance Spectroscopy

\section{Introduction}

Nowadays, photovoltaic performances of organic photovoltaic cells (OPVs) have been drastically improved by optimizing molecular structures of donor polymers 
and device architectures [1] [2] [3] [4]. The red-shifted absorption band of ptype polymer in combination with the bulk heterojunction structure leads to photovoltaic performance higher than $10 \%$. In addition, nanoscale morphology of donor-accepter blend layer is also an important parameter to determine the carrier recombination probability under irradiation of the solar light, which closely correlates with the photovoltaic performance [5] [6] [7]. Because photocurrent generation requires efficient exciton dissociation at the donor-acceptor interface and most of photo excited excitons are deactivated without the donor/ acceptor interface. The optical absorption length is almost same compared to the organic active layer thickness ranging from 80 to $200 \mathrm{~nm}$, but the exciton diffusion length of normal organic semiconductors is shorter. To solve this problem, bulk heterojunction architecture has been used for a long time due to the large interface area between donor-acceptor materials.

In parallel to the synthesis of new polymers, molecular stacking in the active layer, and optimized device structures, evaluation methods of carrier dynamics in OPVs have been developed by many researchers [8] [9] [10] [11]. Several characterization techniques as carrier mobility of organic materials [12] [13], energy level at the interfaces [14] [15], and transient absorption spectroscopy [16] [17] have been investigated to understand carrier dynamics in the OPVs. Impedance spectroscopy is an important tool to discuss carrier dynamics including carrier mobility and density through the equivalent circuit of the device. In this method, the impedance of the device is obtained from the phase difference between the input sinusoidal voltage and the response current. By analyzing the measurement results in a wide frequency range $\left(10^{-3}\right.$ to $\left.10^{6} \mathrm{~Hz}\right)$, it is possible to separate and observe components having various relaxation times contributing to the impedance in the device. In addition, it is one of the features that can measure an actual device because it is a non-destructive measurement method that can be applied to various electronic devices. Especially, one simple interpretation of impedance measurement is that resistance and capacitance components of each layer and each interface can be discriminated from the equivalent circuit [18] [19]. Garcia-Belmonte et al. studied the influence of bias voltage on the depletion layer capacitance and the minority carrier (electron), and evaluated electron mobility and the electron lifetime by fitting the equivalent circuit [20]. The revers bias capacitance generally exhibits Mott-Schottky-like behavior due to the formation of a Schottky junction (band bending) at organic/metal interface in conventional OPVs. In addition, Leever et al. evaluated the electron density and the electron lifetime of OPV as a function of applied voltage by the equivalent circuit with charge transfer resistance and the capacitance of bulk layer and the donor-acceptor interface [21].

Recently, we demonstrated that an improved photovoltaic performance of ITO/ $\mathrm{MoO}_{\mathrm{x}} /$ organic active layer/LiF/Al device drastically by using the annealed$\mathrm{MoO}_{\mathrm{x}}$ layer at $160^{\circ} \mathrm{C}$ [22]. By evaluating the angle-dependent X-ray photoelectron spectroscopy, oxygen vacancies in $\mathrm{MoO}_{\mathrm{x}}$ can be recovered by the annealing 
process, and this fact causes the efficient carrier injection at the $\mathrm{MoO}_{\mathrm{x}}$ /organic interface. Since the $\mathrm{MoO}_{\mathrm{x}}$ layer has been often used as a hole transport layer of the normal OPV device architecture, several researches on the surface of $\mathrm{MoO}_{\mathrm{x}}$ layer have been reported. However, detailed mechanism of efficient carrier transport at the interface of $\mathrm{MoO}_{\mathrm{x}}$ /organic layer is unclear, and further investigation has been required.

In this study, we applied the impedance spectroscopy to bulk heterojunction $\mathrm{OPV}$ with the $\mathrm{MoO}_{\mathrm{x}}$ layer, which was annealed at $160^{\circ} \mathrm{C}$ in the inert condition to reduce surface defects. The resistance and capacitance components in the organic layer can be evaluated using the equivalent circuit. In addition, the relaxation time and electron lifetime of diffusion were evaluated to understand the mechanism of improved photovoltaic performance.

\section{Experimental}

\subsection{Materials}

Poly[4,8-bis(5-(2-ethylhexyl)thiophen-2-yl)benzo[1,2-b;4,5-b']dithiophene-2,6-diyl-alt-(4-(2-ethylhexyl)-3-fluorothieno[3,4-b]thiophene-)-2-carboxylate-2-6-diyl )] (PTB7-Th) and [6,6]-phenyl- $\mathrm{C}_{71}$-butyric acid methyl ester $\left(\mathrm{PC}_{71} \mathrm{BM}\right.$, purity: $>99.0 \%)$ were purchased from 1-Material Inc. and Solene BV, respectively. $\mathrm{MoO}_{\mathrm{x}}$ powder was purchased from Kojundo Chemical Laboratory. These materials were used without further purification.

\subsection{OPV Fabrication}

We fabricated OPV by following procedure. An indium tin oxide (ITO) anode with the thickness of $150 \mathrm{~nm}$ was first patterned on a glass substrate by chemical etching process, and was sequentially treated with acetone, isopropyl alcohol, and pure water using the ultrasonic cleaner. The substrate was then cleaned using the UV ozone cleaner for $20 \mathrm{~min}$. $\mathrm{A} \mathrm{MoO}_{\mathrm{x}}$ layer, used as a hole transport layer, was then thermally evaporated on the ITO layer, controlling the thickness as $40 \mathrm{~nm}$. Then, the sample was annealed at $160^{\circ} \mathrm{C}$ for 5 min under a nitrogen atmosphere to avoid the unexpected oxidation by air (called as device A). For comparison, a reference device was also fabricated using the same process without the annealing step of $\mathrm{MoO}_{\mathrm{x}}$ layer (called as device B). In this research, PTB7Th: $\mathrm{PC}_{71} \mathrm{BM}$ was used as an active layer. $\mathrm{PTB} 7-\mathrm{Th}$ and $\mathrm{PC}_{71} \mathrm{BM}$ were co-dissolved in chlorobenzene at a concentration of $20 \mathrm{mg} / \mathrm{ml}$ in a weight ratio of 1 : 1.5. After adding 1,8-diiodooctane (3 vol\%) in the resulting solution [23], the PTB7-Th: $\mathrm{PC}_{71} \mathrm{BM}$ layer was spin-coated at $2000 \mathrm{rpm}$ for $1 \mathrm{~min}$, and measured thickness was $100 \mathrm{~nm}$. Finally, the $\operatorname{LiF}(0.5 \mathrm{~nm}) / \mathrm{Al}(80 \mathrm{~nm})$ electrode, with an active area of $8 \mathrm{~mm}^{2}$, was thermally deposited in a vacuum deposition chamber.

\subsection{Characterization}

The current density-voltage $(J-V)$ characteristics under irradiation with AM1.5G, $100 \mathrm{~mW} / \mathrm{cm}^{2}$ simulated solar light and external quantum efficiency (EQE) spec- 
tra were measured by the spectral response measurement system (Bunkou Keiki, CEP-25BX). The frequency response of impedance was measured using the impedance analyzer (Iwatsu, PSM1735).

\section{Results and Discussion}

Figure 1(a) and Figure 1(b) show current density-voltage characteristics and EQE spectra of devices $\mathrm{A}$ (with annealing for $\mathrm{MoO}_{\mathrm{x}}$ ) and $\mathrm{B}$ (without annealing for $\mathrm{MoO}_{\mathrm{x}}$ ), respectively. As clearly shown in these results, higher photocurrent and increased EQEs of all the wavelength region from 300 to $900 \mathrm{~nm}$ were observed when the $\mathrm{MoO}_{\mathrm{x}}$ layer was annealed at $160^{\circ} \mathrm{C}$ for $5 \mathrm{~min}$. These results correspond to the increased short circuit current density $\left(J_{s c}\right)$ by a factor of 2.44 shown in Table 1. Calculated photo conversion efficacies (PCEs) of devices A and $\mathrm{B}$ were $5.65 \%$ and $2.05 \%$, respectively. In addition, PCE, $J_{s c}$ open circuit voltage $\left(V_{o c}\right)$ and fill factor $(\mathrm{FF})$ of devices A and B are summarized in Table 1. Especially $J_{s c}$ was improved by the thermal annealing for the $\mathrm{MoO}_{x}$, leading to higher PCE. This trend confirms our previous paper stating that the annealing of $\mathrm{MoO}_{\mathrm{x}}$ is effective for improving photovoltaic performance of OPV [22]. In this previous paper, we conclude that it is the cause of the improvement of the OPV characteristics that oxygen defects that can be electron traps on the surface of $\mathrm{MoO}_{\mathrm{x}}$ are filled by the annealing. In addition, this effect was equally confirmed at a temperature of $160^{\circ} \mathrm{C}$ to $200^{\circ} \mathrm{C}$ and a time of 5 to $30 \mathrm{~min}$ (data not shown). The condition of $160^{\circ} \mathrm{C}$ for $5 \mathrm{~min}$ is a reasonable choice in terms of high compatibility with other processes such as the annealing of P3HT: PCBM [13] [18]

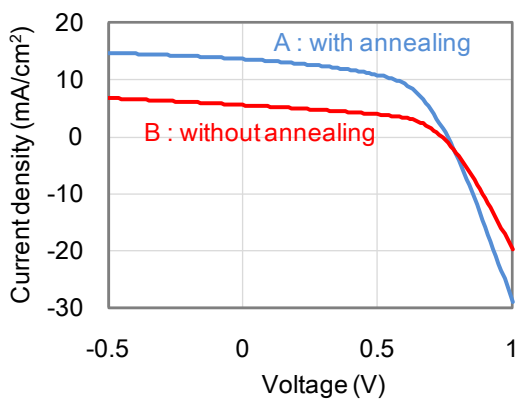

(a)

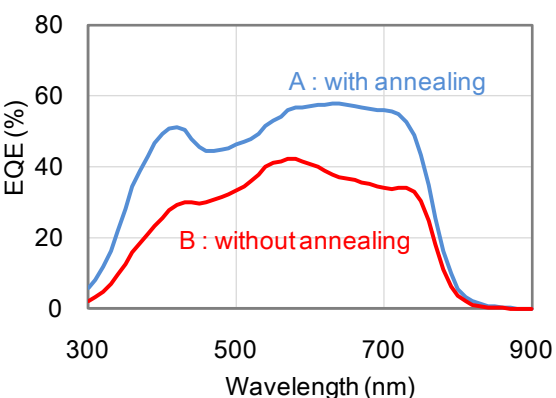

(b)

Figure 1. (a) Current density-voltage characteristics under irradiating AM1.5 solar light and (b) EQE spectra of OPVs fabricated with (device A) and without (device B) annealing process after depositing $\mathrm{MoO}_{\mathrm{x}}$ layer, respectively.

Table 1. Photovoltaic characteristics of devices A and B, which were fabricated with and without annealing for $\mathrm{MoO}_{\mathrm{x}}$ layer.

\begin{tabular}{ccc}
\hline & Device A (with annealing) & Device B (without annealing) \\
\hline PCE (\%) & 5.65 & 2.05 \\
$J_{s c}\left(\mathrm{~mA} / \mathrm{cm}^{2}\right)$ & 13.6 & 5.58 \\
$V_{o c}(\mathrm{~V})$ & 0.76 & 0.74 \\
$\mathrm{FF}$ & 0.55 & 0.50 \\
\hline
\end{tabular}


which are representative materials used as photoactive layer and use of a film substrate.

Figure 2(a) displays the cole-cole plot of devices A (with annealing) and B (without annealing) by the electrical impedance measurement. The bias and AC voltages for the measurement were set as 0 and $100 \mathrm{mV}$, respectively. In addition, measurements were taken in the dark. Impedance spectroscopy is generally performed in the dark, however, when discussing the origin of $V_{O O}$ there is a possibility that it is necessary to perform measurement under light irradiation, the electronic state at the interface changed due to the movement of photo carriers. It can be seen that the cole-cole plots for both devices showed almost same single semicircle shape except for the radius, and the radius was reduced after the annealing process for $\mathrm{MoO}_{\mathrm{x}}$ layer. By assuming a single semicircle, fitting curves matched the impedance spectra well in the whole measurement frequency region from $0.1 \mathrm{~Hz}$ to $1 \mathrm{MHz}$. The radius of semi-circle corresponds to the resistance component of PTB7-Th: $\mathrm{PC}_{71} \mathrm{BM}$ layer [24]. Calculated resistance components of PTB7-Th: $\mathrm{PC}_{71} \mathrm{BM}$ layers in devices $\mathrm{A}$ and $\mathrm{B}$ were 6.5 and $17 \mathrm{M} \Omega$, respectively. This result indicates that the resistance component of PTB7-Th: $\mathrm{PC}_{71} \mathrm{BM}$ layer was reduced after annealing for the $\mathrm{MoO}_{\mathrm{x}}$ layer. The spin-coating conditions of PTB7-Th: $\mathrm{PC}_{71} \mathrm{BM}$ layers for both devices were completely same in our experiment, and molecular orientation of PTB7-Th is same for both devices since the annealing was performed before spin-coating of PTB7-Th: $\mathrm{PC}_{71} \mathrm{BM}$ layer. Therefore, the carrier mobility of PTB7-Th: $\mathrm{PC}_{71} \mathrm{BM}$ was not affected by the annealing process of $\mathrm{MoO}_{\mathrm{x}}$. These facts indicate that the reduced resistance is originated due to the carrier injection at the $\mathrm{MoO}_{\mathrm{x}} / \mathrm{PTB} 7-\mathrm{Th}: \mathrm{PC}_{71} \mathrm{BM}$ interface. Our previous paper demonstrated that surface defects of $\mathrm{MoO}_{x}$, which are caused by the oxygen vacancy of $\mathrm{MoO}_{x}$, were reduced by the annealing process [15]. An efficient carrier injection at the interface of $\mathrm{MoO}_{\mathrm{x}} / \mathrm{PTB} 7-\mathrm{Th}: \mathrm{PC}_{71} \mathrm{BM}$ layer can be realized for the device A.

We also evaluated the carrier transport resistance components as a function of

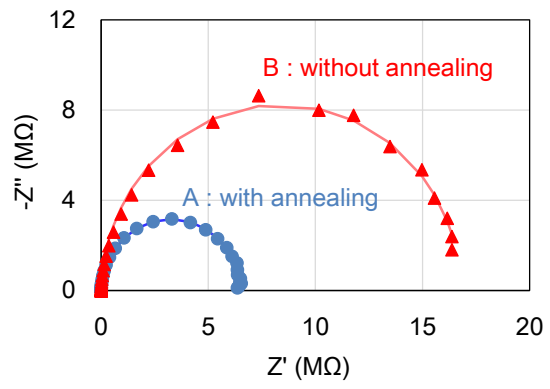

(a)

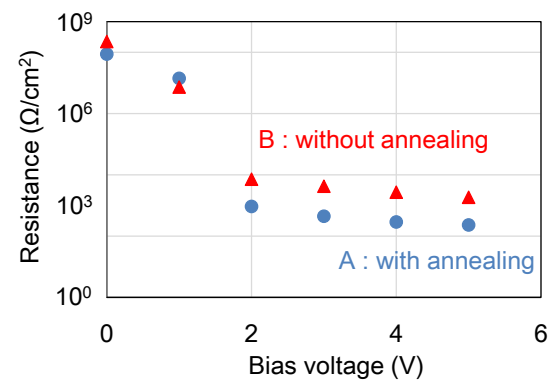

(b)

Figure 2. (a) Impedance cole-cole plots of OPVs, which were fabricated with (device A, blue circle) and without (device $\mathrm{B}$, red triangle) annealing process of $\mathrm{MoO}_{\mathrm{x}}$ layer. The amplitude of sine wave and bias voltages were 0.1 and $0 \mathrm{~V}$, respectively. The blue and red linesare fitting curvesof samples $\mathrm{A}$ and $\mathrm{B}$, respectively; (b) Resistance components of PTB7-Th: $\mathrm{PC}_{71} \mathrm{BM}$ layers, which were calculated from the impedance cole-cope plot, by changing the bias voltage ranging from 0 to $5 \mathrm{~V}$. 
DC bias voltage from impedance measurement. Figure 2(b) shows the relationship between the resistance and the bias voltage ranging from 0 to $5 \mathrm{~V}$ for devices A and B, respectively. Such type of impedance pattern belongs to an ordinary response, in which carrier transport is determined by diffusion-recombination between nano-absorbing contacts [24]. In addition, injected minority carriers (i.e. electrons) from the $\mathrm{Al}$ electrode can diffuse within the PTB7-Th: $\mathrm{PC}_{71} \mathrm{BM}$ active layer and the impedance model consist of an equivalent circuit as shown in Figure 3 [20]. It contains distributed resistors $r_{t}$, which stand for the electron transport, the distributed capacitance $C_{n}$, and recombination resistance $r_{r e c}$ accounting for the electron recombination processes. The $r_{r e c}$ continuously decreased with increasing bias voltage for both cases of devices $\mathrm{A}$ and $\mathrm{B}$ due to the carrier injection by applying DC bias voltage. The electron recombination resistances were reduced by the thermal annealing for all the DC voltage conditions. It implies that the carrier injection efficiency at the $\mathrm{MoO}_{\mathrm{x}} / \mathrm{PTB} 7-\mathrm{Th}: \mathrm{PC}_{71} \mathrm{BM}$ was improved by the thermal annealing of $\mathrm{MoO}_{\mathrm{x}}$ layer. The photovoltaic performance of the device $\mathrm{A}$ is improved after the thermal annealing of $\mathrm{MoO}_{\mathrm{x}}$ [22].

Since both electron recombination resistance and distributed capacitance are known as important parameters to affect the carrier injection/transport at the interface and inside the organic active layer, we then evaluated the modulus cole-cole plot to investigate the capacitance component of PTB7-Th: PC $_{71} \mathrm{BM}$ layer for both devices. Figure 4(a) shows the typical modulus Cole-Cole plots of

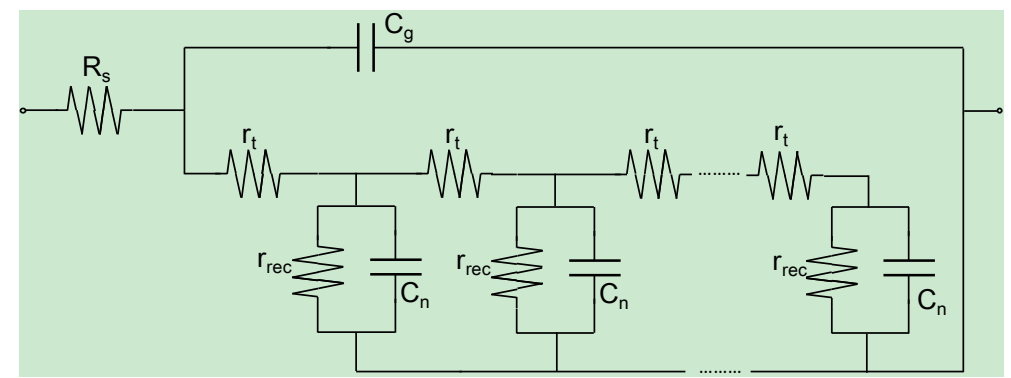

Figure 3. An equivalent circuit of the diffusion-recombination mechanism used for fitting analysis in this study.

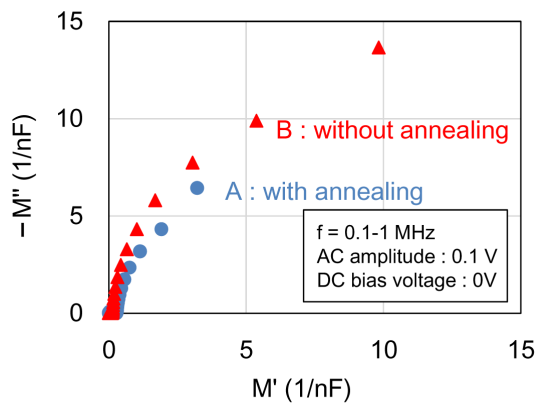

(a)

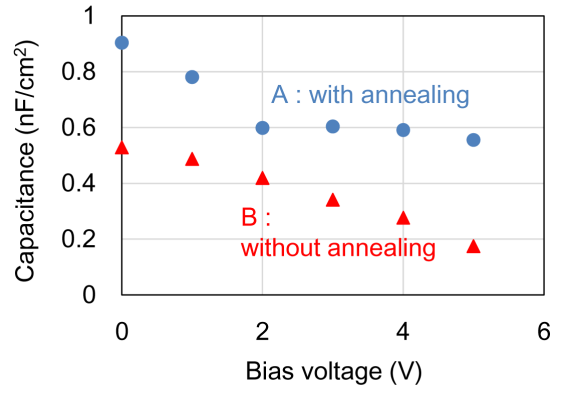

(b)

Figure 4. (a) Modulus cole-cole plots of OPVs, with (blue circle) and without (red triangle) the annealing process of $\mathrm{MoO}_{\mathrm{x}}$ layer; (b) Capacitance components of PTB7-Th: $\mathrm{PC}_{71} \mathrm{BM}$ layers calculated from the impedance cole-cope plot. 
OPVs when the bias voltage was set at $0 \mathrm{~V}$. The measurement frequency range was from $0.1 \mathrm{~Hz}$ to $1 \mathrm{MHz}$, therefore, only the part of semicircle was observed as clearly shown in Figure 4(a). However, the measured modulus cole-cole plot could be fitted as the semicircle by using the Debye relaxation model in the whole measuring frequencies [13]. The radius of modules cole-cole plot, corresponding to the distributed capacitance component $\left(C_{n}\right)$ of PTB7-Th: $\mathrm{PC}_{71} \mathrm{BM}$ layer in Figure 3, increased from $0.040 \mathrm{nF}$ to $0.068 \mathrm{nF}$ after annealing the $\mathrm{MoO}_{\mathrm{x}}$ layer. This result indicates that only the capacitance component of PTB7-Th: $\mathrm{PC}_{71} \mathrm{BM}$ layer increased when the $\mathrm{MoO}_{\mathrm{x}}$ layer was thermally annealed at $160^{\circ} \mathrm{C}$, and was opposite trend of electron recombination resistance component in Figure 2. However, the annealing effect of electron recombination resistance was larger than that of capacitance component, and the reduced electron recombination resistance affects the carrier transport from the PTB7-Th: $\mathrm{PC}_{71} \mathrm{BM}$ layer to the $\mathrm{MoO}_{\mathrm{x}}$ layer.

The red triangle and blue circle correspond to devices fabricated without and with thermal annealing process of $\mathrm{MoO}_{\mathrm{x}}$ layer.

A relaxation time $(\tau)$ is also an important parameter to determine the carrier dynamics of OPV. It can be calculated from the frequency of measurement $\left(f_{m}\right)$ at which the impedance value becomes maximum as

$$
\tau=\frac{1}{2 \pi f_{m}}
$$

Figure 5 shows the imaginary part of impedance $\left(\mathrm{Z}^{\prime \prime}\right)$ as a function of frequency of applied sine wave voltage for different forward bias condition. The peak frequency was drastically shifted toward higher frequency side from $6 \mathrm{~Hz}$ $(0 \mathrm{~V})$ to $167 \mathrm{kHz}(5 \mathrm{~V})$ in device $\mathrm{A} \mathrm{(a)} \mathrm{and} \mathrm{from} 1 \mathrm{~Hz}(0 \mathrm{~V})$ to $29 \mathrm{kHz}(5 \mathrm{~V})$ in device $B(b)$, respectively. It means that the relaxation time was also reduced. The influence of DC bias voltage on the relaxation time of devices A and B is shown in Figure 6. The relaxation time of OPV decreased with increasing the DC bias voltage. The relaxation time of device A was $153 \mathrm{~ms}$, and was reduced down to $27 \mathrm{~ms}$ by annealing the $\mathrm{MoO}_{\mathrm{x}}$ layer (device A) when the DC bias voltage was not applied for the measurement. The small relaxation time corresponds to the efficient carrier transport in the PTB7-Th: $\mathrm{PC}_{71} \mathrm{BM}$ layer. Therefore, this re-

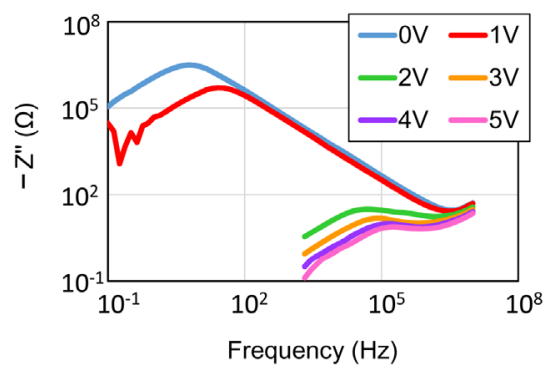

(a)

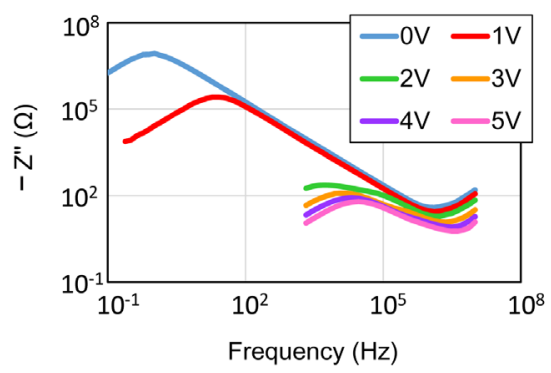

(b)

Figure 5. Relationship between imaginary part of impedance (Im Z") and frequency for (a) device A (with annealing) and (b) device B (without annealing). 


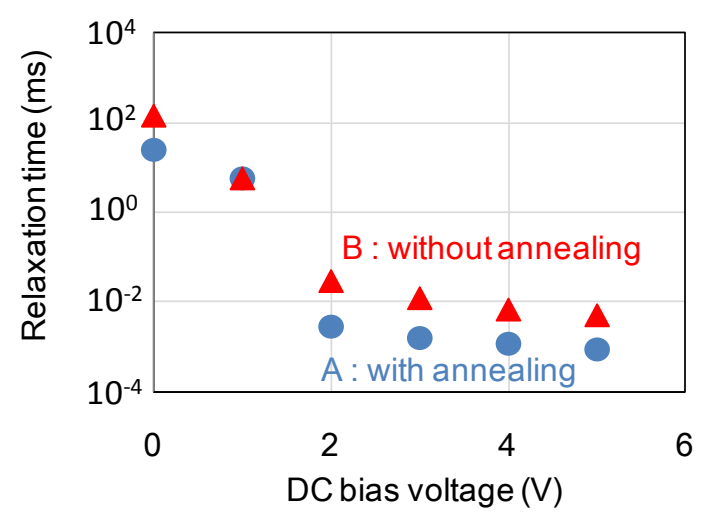

Figure 6. Relaxation time as a function of DC bias voltage for devices A and B, respectively.

sult indicates that the photo generated carriers are efficiently transported forward from the active layer to the electrode, resulting in higher photovoltaic performance. This fact is in good agreement with the device performance shown in Figure 1.

The impedance model mainly contains electron recombination time $\left(\tau_{n}\right)$, which can be calculated by means of the relation [24]

$$
\tau_{n}=r_{\text {rec }} \times C_{n}
$$

where $r_{\text {rec }}$ and $C_{n}$ are the electron recombination resistance and the distributed capacitance in Figure 3, respectively. Figure 7 shows the relationship between the electron recombination time and the DC bias voltage. The electron recombination time was reduced by annealing of the $\mathrm{MoO}_{\mathrm{x}}$ layer. It corresponds to reduced losses due to the electron-hole recombination in the PTB7-Th: $\mathrm{PC}_{71} \mathrm{BM}$ layer, although the surface recombination route cannot be excluded. Therefore, based on these experimental results more efficient carrier dissociation takes place in the device $\mathrm{A}$.

\section{Conclusion}

We fabricated normal OPV with PTB7-Th: $\mathrm{PC}_{71} \mathrm{BM}$ photoactive layer and $\mathrm{MoO}_{\mathrm{x}}$ hole transport layer and investigated the mechanism of improved photo conversion efficiency through impedance spectroscopy. By evaluating the electrical and modulus cole-cole plots, the electron recombination time was calculated from the electron recombination resistance and the distributed capacitance. The electron recombination time decreased by the annealing process for the $\mathrm{MoO}_{\mathrm{x}}$ layer, leading to the efficient carrier dissociation in the PTB7-Th: $\mathrm{PC}_{71} \mathrm{BM}$ layer. In addition, the relaxation time was estimated from the imaginary part of impedance as a function of measuring wavelength. The relaxation time decreased also by the annealing process. Therefore, these facts indicate that the photo-induced carriers were efficiently extracted from the PTB7-Th: $\mathrm{PC}_{71} \mathrm{BM}$ layer, resulting in the higher PCE. In the future, this nondestructive evaluation method can be applied to in-line evaluation by improving measurement accuracy and speed, thereby contributing to improvement of OPV productivity and reliability. 


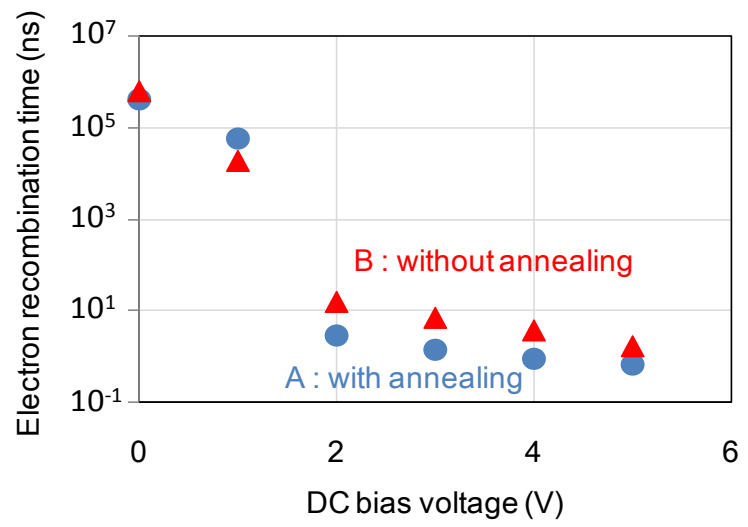

Figure 7. Electron recombination times of devices A and B as a function of DC bias voltage.

\section{Acknowledgements}

The authors gratefully acknowledge the support from the JSPS KAKENHI project (No. 26420267).

\section{References}

[1] Etxebarria, I., Ajuria, J. and Pacios, R. (2015) Solution-Processable Polymeric Solar Cells: A Review on Materials, Strategies and Cell Architectures to Overcome 10\%. Organic Electronics, 19, 34-60. https://doi.org/10.1016/j.orgel.2015.01.014

[2] Luo, G., Ren, X., Zhang, S., Wu, H., Choy, W.C.H., He, Z. and Cao, Y. (2016) Recent Advances in Organic Photovoltaics: Device Structure and Optical Engineering Optimization on the Nanoscale. Small, 12, 1547-1571. https://doi.org/10.1002/smll.201502775

[3] Cao, W. and Xue, J.G. (2014) Recent Progress in Organic Photovoltaics: Device Architecture and Optical Design. Energy and Environmental Science, 7, 2123-2144. https://doi.org/10.1039/c4ee00260a

[4] Kobori, T., Kamata, N. and Fukuda, T. (2017) Effect of Optical Intensity Distribution on Conversion Efficiency of Inverted Organic Photovoltaic Cell. IEICE Transactions on Electronics, E100-C, 114-117. https://doi.org/10.1587/transele.E100.C.114

[5] Hedley, G.J., Ward, A.J., Alekseev, A., Howells, C.T., Martins, E.R., Serrano, L.A., Cooke, G., Ruseckas, A. and Samuel, I.D.W. (2013) Determining the Optimummorphology in High-Performance Polymerfullerene-Organic Photovoltaic Cells. Nature Communications, 4, 2867-2876. https://doi.org/10.1038/ncomms3867

[6] Roehling, J.D., Baran, D., Sit, J., Kassar, T., Ameri, T., Unruh, T., Brabec, C.J. and Moulé, A.J. (2016) Nanoscale Morphology of PTB7 Based Organic Photovoltaics as a Function of Fullerene Size. Scientific Reports, 4, 30915-30926. https://doi.org/10.1038/srep30915

[7] Takahira, K., Toda, A., Suzuki, K. and Fukuda, T. (2017) Highly Efficient Organic Photovoltaic Cells Fabricated by Electrospray Deposition Using a Non-Halogenated Solution. Physica Status Solidi A, 216, 1600536. https://doi.org/10.1002/pssa.201600536

[8] Ie, Y. and Aso, Y. (2017) Development of Donor-Acceptor Copolymers Based on Dioxocycloalkane-Annealed Thiophenes as Acceptor Units for Organic Photovoltaic Materials. Polymer Journal, 49, 13-22. https://doi.org/10.1038/pj.2016.96 
[9] Saito, M., Osaka, I., Suzuki, Y., Takimiya, K., Okabe, T., Ileda, S. and Asano, T. (2015) Highly Efficient and Stable Solar Cells Based on Thiazolothiazole and Naphthobisthiadiazole Copolymers. Scientific Reports, 5, 14202. https://doi.org/10.1038/srep14202

[10] Fukuda, T., Toda, A., Takahira, K., Kuzuhara, D. and Yoshimoto, N. (2017) Improved Performance of Organic Photovoltaic Cells with PTB7-Th: PC ${ }_{71}$ BM by Optimizing Solvent Evaporation Time in Electrospray Deposition. Organic Electronics, 48, 96-105. https://doi.org/10.1016/j.orgel.2017.05.049

[11] Toda, A., Takahira, K., Suzuki, K., Fukuda, T., Hirahara, M., Kamata, N. and Honda, Z. (2016) Spectroscopic Study of P3HT: PCBM Deposited by Electrospray Deposition. Polymer Bulletin, 73, 2457-2462. https://doi.org/10.1007/s00289-016-1673-8

[12] Manaka, T., Lim, E., Tamura, R. and Iwamoto, M. (2007) Direct Imaging of Carrier Motion in Organic Transistors by Optical Second-Harmonic Generation. NaturePhotonics, 1, 581-584. https://doi.org/10.1038/nphoton.2007.172

[13] Honsho, Y., Miyakai, T., Sakurai, T., Saeki, A. and Seki, S. (2013) Evaluation of Intrinsic Charge Carrier Transport at Insulator-Semiconductor Interfaces Probed by a Non-Contact Microwave-Based Technique. Scientific Reports, 3, 3182-3187. https://doi.org/10.1038/srep03182

[14] Nie, W., Gupta, G., Crone, B.K., Liu, F., Smith, D.L., Ruden, P.P., Kuo, C.-Y., Tsai, H., Wang, H.-L., Li, H., Tretiak, S. and Mohite, A.D. (2015) Interface Design Principles for High-Performance Organic Semiconductor Devices. Advanced Science, 2, Article ID: 1500024.

[15] Davis, R. J., Lloyd, M.T., Ferreira, S.R., Bruzek, M.J., Watkins, S.E., Lindell, L., Sehati, P., Fahlman, M., Anthony, J.E. and Hsu, J.W.P. (2011) Determination of Energy Level Alignment at Interfaces of Hybrid and Organic Solar Cells under Ambient Environment. Journal of Materials Chemistry, 21, 1721-1729. https://doi.org/10.1039/C0JM02349C

[16] Singh, S. and Vardeny, Z.V. (2011) Ultrafast Transient Spectroscopy of Polymer/Fullerene Blends for Organic Photovoltaic Applications. Materials, 6, 897-910. https://doi.org/10.3390/ma6030897

[17] Grancini, G., Polli, D., Fazzi, D., Cabanillas-Gonzalez, J., Cerullo, G. and Lanzani, G. (2011) Transient Absorption Imaging of P3HT: PCBM Photovoltaic Blend: Evidence for Interfacial Charge Transfer State. The Journal of Physical Chemistry Letters, 2, 1099-1105. https://doi.org/10.1021/jz200389b

[18] Xu, L., Lee, Y.-J. and Hsu, W.P. (2014) Charge Collection in Bulk Heterojunction Organic Photovoltaic Devices: An Impedance Spectroscopy Study. Applied Physics Letter, 105, Article ID: 123904. https://doi.org/10.1063/1.4896633

[19] Okachi, T., Nagase, T., Kobayashi, T. and Naito, H. (2008) Determination of Charge-Carrier Mobility in Organic Light-Emitting Diodes by Impedance Spectroscopy in Presence of Localized States. Japanese Journal of Applied Physics, 47, 8965-8972. https://doi.org/10.1143/JJAP.47.8965

[20] Garcia-Belmonte, G., Munar, A., Barea, E.M., Bisquert, J., Ugarte, I. and Pacios, R. (2008) Charge Carrier Mobility and Lifetime of Organic Bulk Heterojunctions Analyzed by Impedance Spectroscopy. Organic Electronics, 9, 847-851. https://doi.org/10.1016/j.orgel.2008.06.007

[21] Leever, B.J., Bailey, C.A., Marks, T.J., Hersam, M.C. and Durstock, M.F. (2012) In Situ Characterization of Lifetime and Morphology in Operating Bulk Heterojunction Organic Photovoltaic Devices by Impedance Spectroscopy. Advanced Energy 
Materials, 2, 120-128. https://doi.org/10.1002/aenm.201100357

[22] Kobori, T., Norihiko, K. and Fukuda, T. (2016) Effect of Annealing-Induced Oxidation of Molybdenum Oxide on Organic Photovoltaic Device Performance. Organic Electronics, 9, 847-851.

[23] Zhang, S., Ye, L. and Hou, J. (2016) Breaking the 10\% Efficiency Barrier in Organic Photovoltaics: Morphology and Device Optimization of Well-Known PBDTTT Polymers. Advanced Energy Materials, 6, Article ID: 1502529. https://doi.org/10.1002/aenm.201502529

[24] Sharma, R., Lee, H., Gupta, V., Kim, H., Kumar, M., Sharma, C., Chand, S., Yoo, S. and Gupta, D. (2016) Photo-Physics of PTB7, PCBM and ICBA Based Ternary Solar Cells. Organic Electronics, 34, 111-117. https://doi.org/10.1016/j.orgel.2016.04.022

Submit or recommend next manuscript to SCIRP and we will provide best service for you:

Accepting pre-submission inquiries through Email, Facebook, LinkedIn, Twitter, etc. A wide selection of journals (inclusive of 9 subjects, more than 200 journals)

Providing 24-hour high-quality service

User-friendly online submission system

Fair and swift peer-review system

Efficient typesetting and proofreading procedure

Display of the result of downloads and visits, as well as the number of cited articles Maximum dissemination of your research work

Submit your manuscript at: http://papersubmission.scirp.org/

Or contact ampc@scirp.org 